\title{
Effect of Flaxseed Intervention on Inflammatory Marker C-Reactive Protein: A Systematic Review and Meta-Analysis of Randomized Controlled Trials
}

\author{
Guan-Yu Ren ${ }^{1,2,+}$, Chun-Yang Chen ${ }^{1,2,+}$, Guo-Chong Chen ${ }^{1}$, Wei-Guo Chen ${ }^{2}$, An Pan ${ }^{3}$, \\ Chen-Wei Pan ${ }^{1}$, Yong-Hong Zhang ${ }^{1}$, Li-Qiang Qin ${ }^{1}$ and Li-Hua Chen ${ }^{1}$ ** \\ 1 Jiangsu Key Laboratory of Preventive and Translational Medicine for Geriatric Diseases, \\ Department of Nutrition and Food Hygiene, School of Public Health, Soochow University, 199 Renai Road, \\ Dushu Lake Higher Education Town, Suzhou 215123, China; 15850177665@163.com (G.-Y.R.); \\ chen20154232027@126.com (C.-Y.C.); lsguorong@126.com (G.-C.C.); chwpan@suda.edu.cn (C.-W.P.); \\ yhzhang@suda.edu.cn (Y.-H.Z.); qinliqiang@suda.edu.cn (L.-Q.Q.) \\ 2 Department of Urology, The First Affiliated Hospital of Soochow University, Soochow University, \\ 188 Shizi street, Suzhou 215006, China; 15312172967@163.com \\ 3 Department of Epidemiology and Biostatistics, MOE Key Lab of Environment and Health, \\ School of Public Health, Tongji Medical College, Huazhong University of Science and Technology, \\ 13 Hangkong Road, Wuhan 430030, China; panan@hust.edu.cn \\ * Correspondence: chenlihua@suda.edu.cn; Tel.: +86-512-65880075; Fax: +86-512-65883323 \\ + These authors contributed equally to this work.
}

Received: 27 November 2015; Accepted: 24 February 2016; Published: 4 March 2016

\begin{abstract}
Functional food-flaxseed and its derivatives (flaxseed oil or lignans) are beneficial for human health, possibly because of their anti-inflammatory effects. C-reactive protein (CRP), a sensitive marker of inflammation was chosen to evaluate the anti-inflammatory effects of flaxseed. We searched randomized controlled trials from PubMed and the Cochrane Library in October 2015 and conducted a meta-analysis to evaluate the effectiveness of flaxseed and its derivatives on CRP. The mean differences (net change) in CRP $(\mathrm{mg} / \mathrm{L})$ concentrations were pooled with a random- or a fixed-effects model depending on the results of heterogeneity tests. Overall, flaxseed interventions had no effects on reduction of CRP $(p=0.428)$. The null effects were consistent in the subgroup analysis with multiple studies and population characteristics. Significant heterogeneity was observed in most of the analyses. Meta-regression identified baseline body mass index (BMI) as a significant source of heterogeneity ( $P$-interaction $=0.032)$, with a significant reduction in CRP of $0.83 \mathrm{mg} / \mathrm{L}(95 \%$ confidence interval -1.34 to $-0.31 ; p=0.002$ ) among subjects with a BMI of $\geqslant 30 \mathrm{~kg} / \mathrm{m}^{2}$. In conclusion, our meta-analysis did not find sufficient evidence that flaxseed and its derivatives have a beneficial effect on reducing circulating CRP. However, they may significantly reduce CRP in obese populations.
\end{abstract}

Keywords: flaxseed; C-reactive protein; randomized controlled trials; meta-analysis

\section{Introduction}

Cardiovascular disease (CVD) is the leading cause of mortality worldwide [1]. A growing body of evidence suggests that inflammation is a key feature in CVD and its risk factors, such as abdominal obesity, metabolic syndrome and type 2 diabetes (T2D) [2]. The changes in the degree of inflammation could be reflected in the fluctuations in the levels of C-reactive protein (CRP), a sensitive marker of inflammation. According to meta-analyses of long-term prospective studies, increased levels of inflammatory marker CRP were strongly positively associated with CVD risk [3,4]. Several dietary factors, such as plant sterols, fiber, isoflavones and omega-3 (n-3) polyunsaturated fatty acids (PUFAs, including eicosapentaenoic acid (EPA), docosahexaenoic acid (DHA), and a-linolenic acid (ALA)) 
have been shown to be cardiovascular protective based on accumulating evidence from randomized controlled trials (RCTs) [5-7]. Reducing inflammation has been recognized as one of the numerous mechanisms by which they may reduce the risk of CVD [6,8]. Flaxseed (linseed, Linum usitatissimum), an edible oil seed/grain, is emerging as an attractive functional food with the richest plant source of ALA (50\%-62\% of flaxseed oil, or $22 \%$ of whole flaxseed) and lignans (a class of phytoestrogen, range: 0.2-13.3 mg/g flaxseed) [9-11]. In addition, flaxseed contains abundant dietary fiber (28\% by weight), a third of which is soluble fiber [9-11].

ALA has been shown to have anti-inflammatory effects through the downregulation of the expression of hepatic inflammatory genes in diabetic rats and a remarkable reduction of plasma CRP levels in rats fed with a high-fat diet $[12,13]$. Whole flaxseed supplementation has been shown to mitigate pathophysiology of atherosclerosis in myocardial ischemia rat models through decreasing levels of inflammatory markers [14].

The special composition of flaxseed and its possible mechanisms in CVD protection inspire many researchers to perform clinical trials to determine the outcomes of flaxseed intervention (whole flaxseed, flaxseed oil, or lignans) on various cardiovascular risk factors, particularly inflammation status reflected in inflammatory marker levels of CRP [11,15-33]. However, the findings from those clinical trials were inconsistent, and the discrepancies may be attributable to aspects of the study design (e.g., study power, the patient recruited, sample size, study duration, flaxseed or its derivatives dose used). Therefore, we performed a meta-analysis of published RCTs to evaluate whether administration of flaxseed or its derivatives could ameliorate inflammation status.

\section{Methods}

\subsection{Literature Search}

We made attempts to follow the Preferred Reporting Items for Systematic Reviews and Meta-Analysis (PRISMA) guidelines in the report of this meta-analysis and registered our report in PROSPERO (International prospective register of systemic reviews; CRD42016034184) [34]. Two researchers (G.-Y.R. and C.-Y.C) independently searched PubMed and the Cochrane Library for English-language reports of clinical trials published in October 2015. Studies describing the effects of flaxseed or its derivatives (in the form of whole or ground flaxseed, flaxseed oil, or lignan supplement) in adults were selected. The following keywords were applied to the search: ("C-reactive protein" OR CRP OR inflammation) AND (flax* OR linseed OR lignan OR “Linum usitatissimum"). For literature search in PubMed, the filters, such as Full text, Humans and English were activated. The search in the Cochrane Library was limited to Trials (the detailed search strategy is shown in Table S1). Additionally, the reference lists of selected studies and relevant reviews [10,35-39] were also checked to ensure a complete collection. Attempts were also made to contact investigators for unpublished data.

\subsection{Study Selection}

Studies were included for analysis if they met the following criteria: (1) The subjects consumed flaxseed or its derivatives for at least 2 weeks; (2) the study was an RCT with either a parallel or crossover design; (3) the study reported the dose of flaxseed, lignans, or flaxseed oil (or ALA); and (4) the effects of flaxseed or its derivatives on inflammatory marker CRP could be extracted from the report.

\subsection{Data Extraction and Quality Assessment}

The following information was extracted and tabulated for analysis: authors, publication year, sample size and attrition, dose and type of the intervention, control treatment, study duration, study design (crossover or parallel), participant information (sex, age, health status), and CRP data. The study quality was assessed with the Jadad score (randomization, blinding, description of withdrawals and dropouts, methods of randomization, and double-blinding status) for RCTs [40]. The total score was the sum of the 5 points, which generated a scale from 0 to 5; higher numbers represented better quality. 


\subsection{Statistical Analysis}

The effect was defined as the mean difference (net change) in CRP $(\mathrm{mg} / \mathrm{L})$ concentrations. For parallel trials, the net changes were calculated using the difference (intervention minus control) of the changes (final values minus baseline values) of the mean values. For cross-over trials, the net changes were calculated as the difference of mean values at the end of the intervention and control periods. Where necessary, standard errors and confidence intervals (CIs) were converted to standard deviations (SDs) for the analysis. The SDs for changes from baseline in the intervention and control groups were obtained. If not specified in the original paper, we computed the missing SDs using the method proposed by Follmann et al. [41], where a correlation coefficient of 0.5 was assumed.

The heterogeneity of the effect sizes among studies was tested using the $I^{2}$ and the Cochrane $Q$ tests statistics. Either a fixed-effect or random-effects model (in the presence of heterogeneity, $p$ value for $Q$ test $<0.1$ or $I^{2}>50 \%$ ) was used to calculate the combined effect size. The influence of a single study on the overall effect estimate was investigated by omitting one study in each turn. Meta-regression was implemented to examine characteristics of the studies that were hypothesized as influencing the observed treatment effects. We further conducted pre-specified subgroup analysis stratified by type of intervention (whole flaxseed, flaxseed oil or flaxseed lignan), intervention dose, study duration, study design, study sample size, study quality score (measured with the Jadad score), participant gender, participant BMI, participant age, and baseline CRP level. Publication bias was evaluated with the Funnel plots and Egger's regression model.

All analyses were performed using STATA version 11.0 (StataCorp, College Station, TX, USA). $p<0.05$ was deemed statistically significant, except where otherwise specified.

\section{Results}

\subsection{Study Selection}

A total of 219 citations (171 items from PubMed and 48 items from the Cochrane Library) was yielded from the literature search (search strategy in Table S1). After the title and abstract screening, 33 items were retrieved for more detailed reviews. A total of 13 reports were excluded after carefully reading the full reports (see Table S2). Finally, we identified 20 studies that were suitable for our meta-analysis (Figure 1).

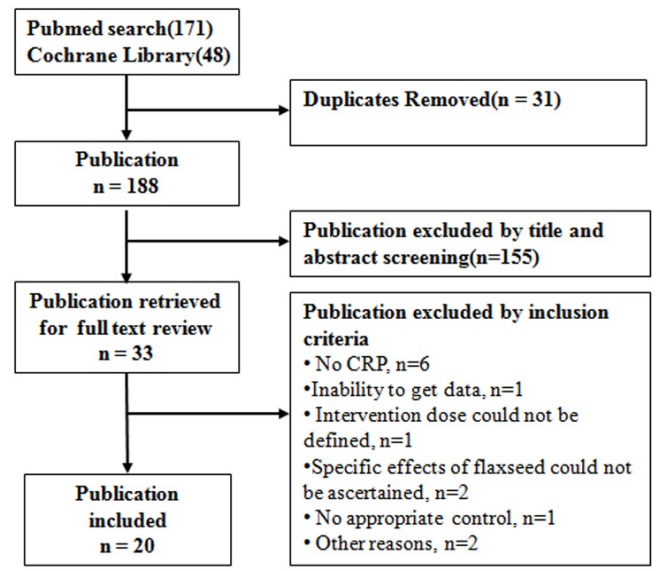

Figure 1. Flow chart of study selection.

\subsection{Characteristics of the Studies}

The primary characteristics of these 20 studies are outlined in Table 1 . Overall, 1378 subjects were randomly assigned in these trials, and $1213(88 \%)$ participants completed the studies. The mean age of the participants ranged from 25.6 to 65 years old. Among the 20 trials, 5 were conducted exclusively on women $[15,17,20,21,32], 2$ were on men [16,30], and the other 13 were on both genders (1 trial did not indicate the gender composition [28]). 
Table 1. Characteristics of the 20 included studies, with 22 comparisons.

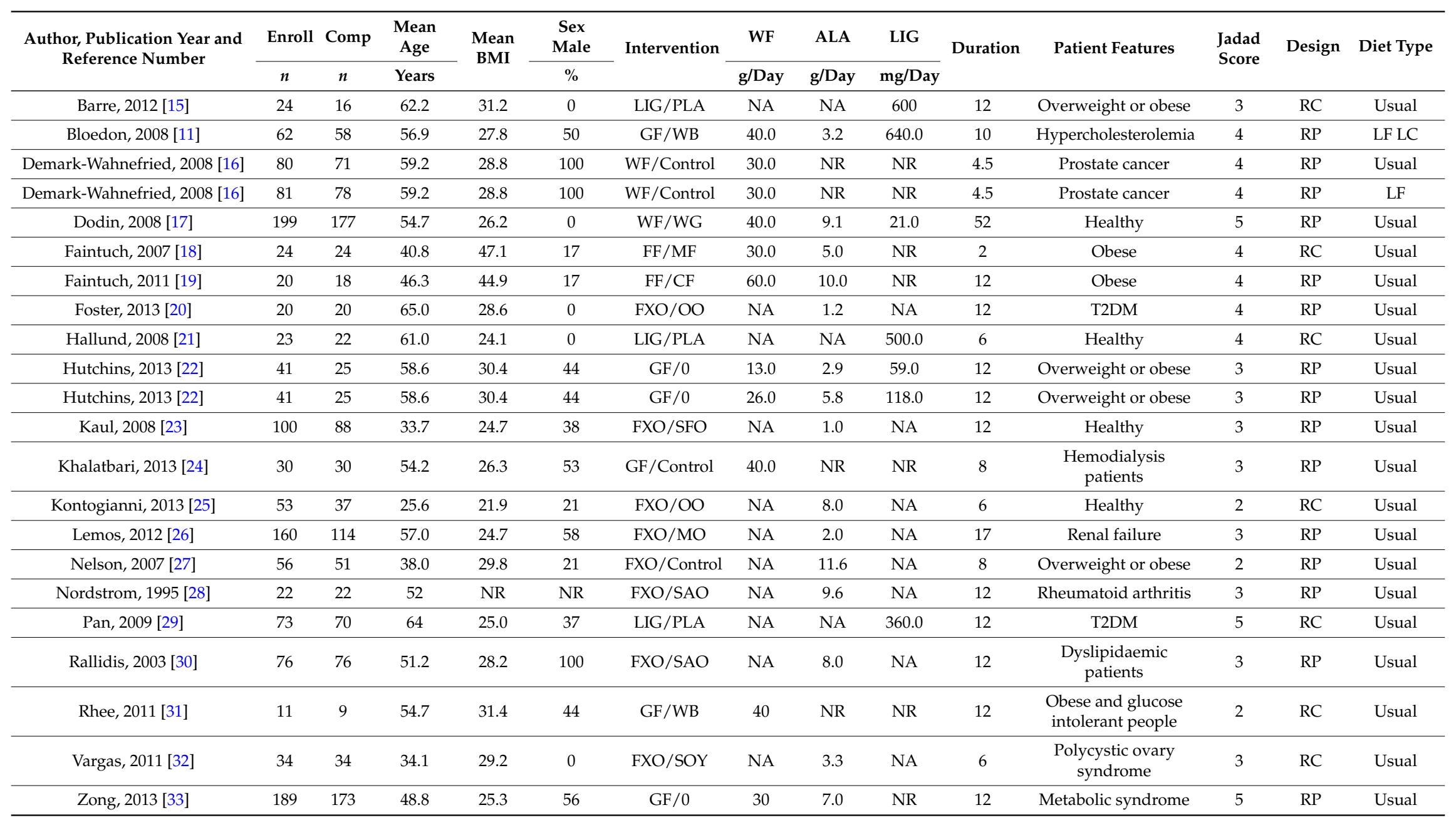

ALA: $\alpha$-linolenic acid; BMI: body mass index; CF: cassava flour; Comp: completer; Enroll: enrollment; FF: flaxseed flour; FXO: flaxseed oil; GF: ground flaxseed; LC: low cholesterol

LF: low fat; LIG: lignans; MF: manioc flour; NA: not applicable; NR: not reported; OO: olive oil; PLA: placebo; RC: randomized crossover design; RP: randomized parallel design; SAO: safflower oil; Soyb: soybean oil; SFO: sunflower oil; T2DM: type 2 diabetes mellitus; WB: wheat bran; WF: whole flaxseed; WG: wheat germ. 
Flaxseed in whole $[16,17]$, ground $[11,22,24,31,33]$ or flour $[18,19]$ form was tested in 9 trials with doses from 13.0 to $60.0 \mathrm{~g} /$ day (median: $30.0 \mathrm{~g} /$ day). Wheat, wheat bran/germ, or manioc flour were employed as the control regimen in these studies. However, in one study [16], participants in the control arm were allocated to low-fat diets, whereas participants in the intervention arm received a low-fat diet plus additional flaxseed (30 g/day). In another study [11], all the participants in both control and intervention group were asked to follow low-fat, low-cholesterol diets. Flaxseed oil has been tested in another 8 trials $[20,23,25-28,30,32]$, with doses ranging from 1.0 to $11.6 \mathrm{~g}$ / day for ALA (median: $5.65 \mathrm{~g} /$ day). The control regimens included oils enriched in the monounsaturated fatty acids (MUFAs) olive oil $[20,25]$ or in the polyunsaturated omega-6 fatty acid safflower, sunflower oil, or soybean oil [23,28,30,32]. In the remaining 3 trials [15,21,29], flaxseed lignan supplement was used and the doses were 360,500 , and $600 \mathrm{mg} /$ day, respectively. The controls were assigned to placebo.

The trials varied in length from 2 to 52 weeks, with a median duration of 12 weeks. Most of the trials (13 trials) adopted a parallel study design $[11,16,17,19,20,22-24,26-28,30,33]$, whereas the other 7 trials used a crossover design $[15,18,21,25,29,31,32]$. In most studies, the participants were instructed to maintain their dietary habits, except the two low-fat trials $[11,16]$. The investigators attempted to provide similar amounts of total fat and saturated fat in both the intervention and control arms.

\subsection{Changes in CRP Concentration}

The net changes and corresponding 95\% CIs for CRP (22 comparisons from 20 studies) was presented in Figure 2. Flaxseed or its derivatives non-significantly changed CRP $(-0.13 \mathrm{mg} / \mathrm{L}$; 95\% CI: -0.44 to $0.19 ; p=0.428$; Figure 2 ). Because the test for heterogeneity was significant for CRP $\left(I^{2}=63.8 \%, p<0.001\right)$, we reported the results from the random-effects model.

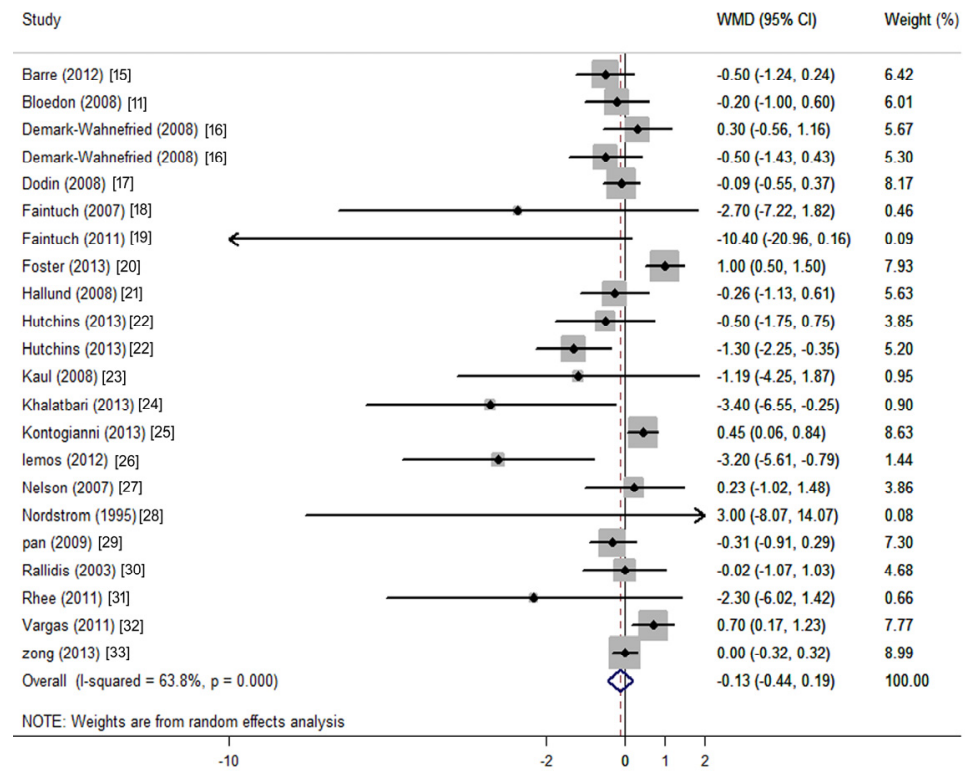

Figure 2. Meta-analysis of flaxseed intervention on net changes ( $95 \% \mathrm{CI})$ of CRP. CI: confidence interval. WMD: weighted mean difference; The horizontal lines denote the $95 \%$ CIs: some of which extend beyond the limits of the scales. The square represents the point estimate of each study. The diamond represents the overall pooled estimate of the treatment effect.

\subsection{Subgroup and Meta-Regression Analysis for CRP}

Considering that the basal levels of CRP, type of study design (parallel or crossover design), study quality (measured with the Jadad score), study duration, sex composition, age, body mass index (BMI), type of intervention (whole flaxseed, flaxseed oil, or lignan supplement), and intervention dose may influence the net changes of CRP, we conducted meta-regression analysis based on these 
variables. We detected sources of heterogeneity according to multiple pre-defined study and population characteristics and found that the type of intervention $(p=0.008)$, baseline BMI $(p=0.032)$, and possibly baseline CRP ( $p=0.064)$ contributed to the heterogeneity among studies, but only the stratum of obese populations showed significant results in CRP reduction $(-0.83 \mathrm{mg} / \mathrm{L} ; 95 \% \mathrm{CI}:-1.34$ to $-0.31 ; p=0.002)$ (Table 2). Among the strata of whole flaxseed intervention, lignan intervention and participants with higher BMI showed non-significant tendencies toward reduced CRP, which may be due to a low statistical power resulting from small effect of flaxseed and/or small sample size included (Table 2).

Table 2. Pooled estimates of effects on CRP within various subgroups.

\begin{tabular}{|c|c|c|c|c|c|c|}
\hline Subgroups & $\begin{array}{c}\text { No. of } \\
\text { Comparisons }\end{array}$ & Net Change (95\% CI) & $\begin{array}{c}p \text { for } \\
\text { Interaction }\end{array}$ & $I^{2}$ & $\begin{array}{c}p \text { for } \\
\text { Heterogeneity }\end{array}$ & $\begin{array}{l}\text { Analysis } \\
\text { Models }\end{array}$ \\
\hline \multicolumn{7}{|c|}{ Type of intervention } \\
\hline Flaxseed oil & 8 & $0.39(-0.09,0.87)$ & & $55.6 \%$ & 0.027 & Random-effect \\
\hline Lignan & 3 & $-0.36(-0.77,0.05)$ & & $0.00 \%$ & 0.089 & Fixed-effect \\
\hline \multicolumn{7}{|c|}{ Dose of whole flaxseed } \\
\hline$\geqslant 40 \mathrm{~g}$ & 5 & $-0.63(-1.62,0.36)$ & & $55.4 \%$ & 0.062 & Random-effect \\
\hline \multicolumn{7}{|c|}{ ( $0.00(1.02,0.00)$} \\
\hline$<10 \mathrm{mg} / \mathrm{L}$ & 19 & $-0.10(-0.41,0.21)$ & 0.064 & $65.7 \%$ & $<0.0001$ & Random-effect \\
\hline$\geqslant 10 \mathrm{mg} / \mathrm{L}$ & 3 & $-3.04(-6.93,0.85)$ & & $34.1 \%$ & 0.220 & Fixed-effect \\
\hline \multicolumn{7}{|l|}{ BMI } \\
\hline \multicolumn{7}{|l|}{ Gender } \\
\hline Female & 4 & $0.30(-0.34,0.95)$ & 0.191 & $82.1 \%$ & 0.001 & Random-effect \\
\hline Male & 3 & $-0.06(-0.60,0.49)$ & & $0.00 \%$ & 0.464 & Fixed-effect \\
\hline Both & 15 & $-0.39(-0.82,0.04)$ & & $57.6 \%$ & 0.003 & Random-effect \\
\hline \multicolumn{7}{|l|}{ Study design } \\
\hline Crossover & 7 & $0.01(-0.47,0.49)$ & 0.638 & $65.9 \%$ & 0.015 & Random-effect \\
\hline Parallel & 15 & $-0.23(-0.66,0.20)$ & & $61.9 \%$ & $<0.0001$ & Random-effect \\
\hline \multicolumn{7}{|l|}{ Study duration } \\
\hline$<12$ weeks & 9 & $0.09(-0.31,0.50)$ & 0.649 & $48.9 \%$ & 0.048 & Random-effect \\
\hline$\geqslant 12$ weeks & 13 & $-0.31(-0.77,0.16)$ & & $69.1 \%$ & $<0.0001$ & Random-effect \\
\hline \multicolumn{7}{|l|}{ Sample size } \\
\hline$<4$ & 12 & $-0.39(-0.97,0.20)$ & 0.902 & $68.1 \%$ & $<0.0001$ & Random-effect \\
\hline$\geqslant 4$ & 10 & $-0.32(-0.37,0.37)$ & & $61.6 \%$ & 0.005 & Random-effect \\
\hline
\end{tabular}

$p$ for interaction: for heterogeneity between subgroups with meta-regression analysis.

\subsection{Publication Bias}

Both the funnel plot and Egger's test $(p=0.007)$ showed evidence of publication bias in CRP (Figure 3). 


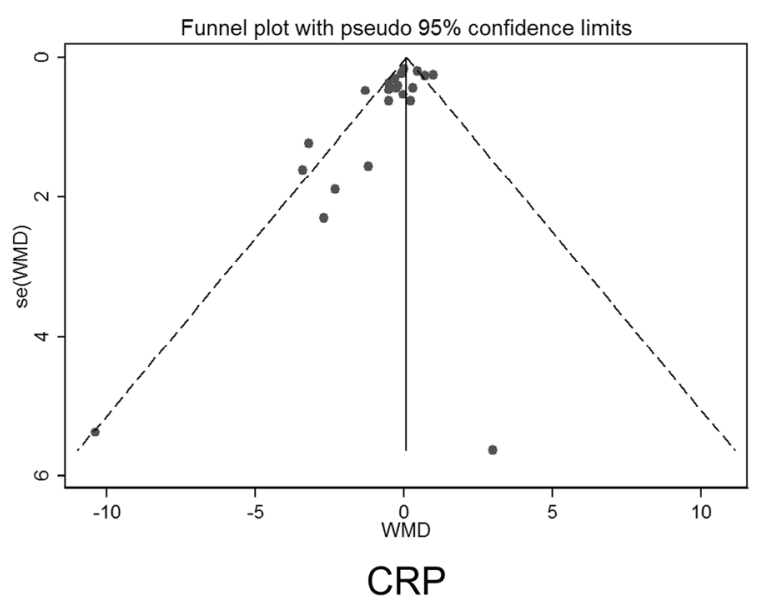

Figure 3. Funnel plots for testing publication bias.

\section{Discussion}

This meta-analysis provides evidence of no general benefit of flaxseed or its derivatives supplementation on decreasing CRP levels. However, the supplementation significantly decreased CRP levels in studies, where the recruited participants' BMI were over $30 \mathrm{~kg} / \mathrm{m}^{2}$.

Many studies have repeatedly shown that obese [42] or elderly [43] people tend to have higher blood levels of CRP, and people with chronically elevated levels of inflammation may be most likely to benefit from this intervention [44]. This has been confirmed in the subgroup analysis that CPR level was significantly reduced in studies with mean BMI over $30 \mathrm{~kg} / \mathrm{m}^{2}$ (Table 2). Additionally, we found a trend toward a greater reduction of CPR in age over 50 years (Table 2). Three of the included studies needed to be mentioned individually. The participants recruited by Faintuch et al. $[18,19]$ were morbidly obese with BMIs over $40 \mathrm{~kg} / \mathrm{m}^{2}$. The participants recruited by Nordstrom et al. [28] were subjects with rheumatoid arthritis. CRP levels were over $10 \mathrm{mg} / \mathrm{L}$ in these 3 studies. Clinically, CRP over $10 \mathrm{mg} / \mathrm{L}$ is suggestive of active inflammation or infection [45]. Because the SDs of the net change of CRP were large and sample sizes were very small (around 10 in each group), the weight of these 3 studies is negligible (less than 1\%). An exclusion of these 3 studies from the meta-analysis did not significantly change the pooled results (Table 2). Whether flaxseed intervention could decrease CRP levels in these active inflammatory situations needs to be further studied.

Intake of $n$-3 PUFAs (EPA and DHA) has been shown to have beneficial effects on CVD, diabetes, and other obesity-related diseases [46]. A recent meta-analysis showed that marine-derived $n-3$ PUFAs supplementation had a significant lowering effect on CRP levels [47]. However, it is unclear whether ALA, as a plant-based source of $n-3$ PUFA, has similar effects on chronic diseases and inflammation. Unlike fish oil, ALA is more readily available and quite inexpensive. Flaxseed was considered as an alternative source of marine-derived omega-3 fatty acid, and some studies were conducted to examine its beneficial role in patients with T2D, rheumatoid arthritis, and chronic hemodialysis $[24,32,48]$. However, in our current meta-analysis, we showed that flaxseed oil did not have a significant CRP-lowering effect. One of the plausible explanations for this null result is that the conversion from ALA to EPA or DHA was considered negligible (conversion rate has been suggested to be as low as 5\%) [49]; thus, the biologically effective dose may not be reached through such a conversion. Another explanation for the null findings is that the effects of flaxseed oil may have been masked by the use of MUFA- or $n-6$ PUFA-enriched oils as the control regimen in these studies. Previous studies have shown that, compared to saturated fatty acids, MUFAs and $n-6$ PUFAs also have an inflammation-lowering effect [50,51]. Whether a replacement of MUFAs or $n-6$ PUFAs for saturated or trans fatty acids as the control regimen could lower CRP remains to be elucidated.

Our findings from the meta-analysis showed that whole flaxseed reduced CRP levels and the statistical result was borderline significant. Besides $n-3$ fatty acid, flaxseed is a good source of dietary 
fiber ( $28 \%$ by weight), in particular soluble fiber [9-11]. Dietary fiber can be partially or completely fermented to short chain fatty acids (acetate, propionate, and butyrate). One study showed that propionate downregulated the pro-inflammatory cytokine TNF- $\alpha$ in adipose tissue [52]. Recently, Jiao et al. [53] conducted a meta-analysis and showed that dietary fiber (total fiber intake $8 \mathrm{~g} /$ day higher) significantly reduced CRP levels in overweight and obese adults. Thus, this CRP-lowering effect might be due to the fiber component in whole flaxseed. Lignans are a group of polyphenols with antioxidant prosperities and are abundant in flaxseed (range: $0.2-13.3 \mathrm{mg} / \mathrm{g}$ ) [35]. Although lignans are not classified as dietary fibers, they share some of the chemical characteristics of lignin, which is an insoluble fiber. However, human studies that examine the role of lignans on inflammation are still limited, and whether lignans alone have a CRP-lowering effect needs to be confirmed or refuted.

This meta-analysis included studies that had a relatively high Jadad score. However, it was limited by a potential publication bias, which is revealed by the asymmetry of the funnel plot and the Egger's model. Publication bias suggests that some small studies with negative findings may have been missed or unpublished. Including these studies would further promote our results to a null effect. In addition, there is considerable heterogeneity across studies, which complicated the interpretation of our findings. Given the variation in study characteristics, it is not surprising that there is substantial heterogeneity among individual studies. The participants in these studies are overweight/obese adults, hemodialysis patients with dyslipidaemia, patients with renal failure, patients with rheumatoid arthritis, T2DM or metabolic syndrome, and adults who are defined "healthy". A healthy status may influence the effect of flaxseed or its derivatives on inflammatory response differently. The intestinal microbiota composition varies between healthy and diseased individuals [54]. As the components of flaxseed need to be fermented or metabolized by human intestinal bacteria to exert their biological effects, gut microbiota may also change the effect of flaxseed on inflammatory response [38]. Subgroup analysis results indicated a significantly larger reduction of CRP in subjects with BMIs over $30 \mathrm{~kg} / \mathrm{m}^{2}$. This finding was also supported by meta-regression analysis that BMI was a source of heterogeneity among trials. This result is important because obesity, an established risk factor for CVD, is associated with elevated levels of CRP [55]. A decrease in CRP by flaxseed supplementation is helpful for alleviating the risk of CVD [55]. Although our meta-analysis did not find sufficient evidence that flaxseed and its derivatives have a beneficial effect on reducing circulating CRP in unstratified populations, their CVD prevention role cannot be denied. As is well known, in addition to inflammation, high blood pressure and dyslipidemia are also risk factors of CVD. Recent meta-analysis showed that supplementation with various flaxseed products decreased both systolic blood pressure (BP) and diastolic BP [56]. In additon, a meta-analysis by Pan et al. found that flaxseed reduced circulating total and LDL-cholesterol concentrations [7]. The intervention of whole flaxseed reduced total or LDL cholesterol by $\approx 0.2 \mathrm{mmol} / \mathrm{L}$, which is estimated to have resulted in a reduction of $\approx 3 \%$ in all-cause mortality and of $6 \%$ in both coronary heart disease-related mortality and total events [7,57]. Therefore, the effects of flaxseed on CVD prevention appear to be clinically significant. Thus, functional foods/nutraceutials such as garlic [58], green tea [59], astaxanthin [60] and flaxseed [7], etc. that have been demonstrated to reduce the risk of CVD, are encouraged to be incorporated into our diet, as they might reduce the drug dose, such as statins, the commonly prescribed drugs to prevent cardiovascular events or drug-related side effects as an adjuvant therapy [61]. Our data suggest that future well-designed studies with large sample sizes and adequate durations are needed to investigate the effectiveness of whole flaxseed on inflammatory factors amelioration, particularly in obese populations.

\section{Conclusions}

Our meta-analysis did not find sufficient evidence that flaxseed and its derivatives have a beneficial effect on reducing circulating CRP. However, the supplementation of flaxseed and its derivatives may significantly reduce CRP in obese populations. 
Supplementary Materials: The following are available online at http://www.mdpi.com/2072-6643/8/3/136/s1, Table S1: Literature search strategy for meta-analysis, Table S2: Characteristics of excluded studies and reasons for exclusion.

Acknowledgments: This work was supported by grants from Natural Science Foundation of Jiangsu Province (BK20140372), Postgraduate Innovation Cultivating Project in Jiangsu Province (SJLX_0572).

Author Contributions: L.-H.C., G.-Y.R., and C.-Y.C. designed and performed this research work; and L.-H.C. supervised the research. L.-H.C., G.-Y.R., C.-Y.C. W.-G.C. analyzed the data; L.-H.C, G.-C.C., C.-W.P., A.P., Y.-H.Z. and L.-Q.Q. prepared the manuscript.

Conflicts of Interest: The authors declare no conflict of interest.

\section{References}

1. Kovacic, J.C.; Castellano, J.M.; Fuster, V. Cardiovascular defense challenges at the basic, clinical, and population levels. Ann. N. Y. Acad. Sci. 2012, 1254, 1-6. [CrossRef] [PubMed]

2. Esser, N.; Paquot, N.; Scheen, A.J. Anti-inflammatory agents to treat or prevent type 2 diabetes, metabolic syndrome and cardiovascular disease. Expert Opin. Investig. Drugs 2015, 24, 283-307. [CrossRef] [PubMed]

3. Kaptoge, S.; Di Angelantonio, E.; Lowe, G.; Pepys, M.B.; Thompson, S.G.; Collins, R.; Danesh, J. C-reactive protein concentration and risk of coronary heart disease, stroke, and mortality: An individual participant meta-analysis. Lancet 2010, 375, 132-140. [PubMed]

4. Kaptoge, S.; Seshasai, S.R.; Gao, P.; Freitag, D.F.; Butterworth, A.S.; Borglykke, A.; Di Angelantonio, E.; Gudnason, V.; Rumley, A.; Lowe, G.D.; et al. Inflammatory cytokines and risk of coronary heart disease: New prospective study and updated meta-analysis. Eur. Heart J. 2014, 35, 578-589. [CrossRef] [PubMed]

5. Tanaka, S.; Yoshimura, Y.; Kamada, C.; Tanaka, S.; Horikawa, C.; Okumura, R.; Ito, H.; Ohashi, Y.; Akanuma, Y.; Yamada, N.; et al. Intakes of dietary fiber, vegetables, and fruits and incidence of cardiovascular disease in japanese patients with type 2 diabetes. Diabetes Care 2013, 36, 3916-3922. [CrossRef] [PubMed]

6. Kris-Etherton, P.M.; Harris, W.S.; Appel, L.J. Fish consumption, fish oil, omega-3 fatty acids, and cardiovascular disease. Circulation 2002, 106, 2747-2757. [CrossRef] [PubMed]

7. Pan, A.; Yu, D.; Demark-Wahnefried, W.; Franco, O.H.; Lin, X. Meta-analysis of the effects of flaxseed interventions on blood lipids. Am. J. Clin. Nutr. 2009, 90, 288-297. [CrossRef] [PubMed]

8. Paoletti, R.; Gotto, A.M., Jr.; Hajjar, D.P. Inflammation in atherosclerosis and implications for therapy. Circulation 2004, 109, Iii20-Iii26. [CrossRef] [PubMed]

9. Muir, A.D. Flax lignans-Analytical methods and how they influence our lunderstanding of biological activity. J. AOAC Int. 2006, 89, 1147-1157. [PubMed]

10. Hall, C., 3rd; Tulbek, M.C.; Xu, Y. Flaxseed. Adv. Food Nutr. Res. 2006, 51, 1-97. [PubMed]

11. Bloedon, L.T.; Balikai, S.; Chittams, J.; Cunnane, S.C.; Berlin, J.A.; Rader, D.J.; Szapary, P.O. Flaxseed and cardiovascular risk factors: Results from a double blind, randomized, controlled clinical trial. J. Am. Coll. Nutr. 2008, 27, 65-74. [CrossRef] [PubMed]

12. Jangale, N.M.; Devarshi, P.P.; Dubal, A.A.; Ghule, A.E.; Koppikar, S.J.; Bodhankar, S.L.; Chougale, A.D.; Kulkarni, M.J.; Harsulkar, A.M. Dietary flaxseed oil and fish oil modulates expression of antioxidant and inflammatory genes with alleviation of protein glycation status and inflammation in liver of streptozotocin-nicotinamide induced diabetic rats. Food Chem. 2013, 141, 187-195. [CrossRef] [PubMed]

13. Xu, J.; Yang, W.; Deng, Q.; Huang, Q.; Yang, J.; Huang, F. Flaxseed oil and alpha-lipoic acid combination reduces atherosclerosis risk factors in rats fed a high-fat diet. Lipids Health Dis. 2012, 11, 148. [CrossRef] [PubMed]

14. Nounou, H.A.; Deif, M.M.; Shalaby, M.A. Effect of flaxseed supplementation and exercise training on lipid profile, oxidative stress and inflammation in rats with myocardial ischemia. Lipids Health Dis. 2012, 11, 129. [CrossRef] [PubMed]

15. Barre, D.E.; Mizier-Barre, K.A.; Stelmach, E.; Hobson, J.; Griscti, O.; Rudiuk, A.; Muthuthevar, D. Flaxseed lignan complex administration in older human type 2 diabetics manages central obesity and prothrombosis-an invitation to further investigation into polypharmacy reduction. J. Nutr. Metab. 2012, 2012, 585170. [CrossRef] [PubMed] 
16. Demark-Wahnefried, W.; Polascik, T.J.; George, S.L.; Switzer, B.R.; Madden, J.F.; Ruffin, M.T.; Snyder, D.C.; Owzar, K.; Hars, V.; Albala, D.M.; et al. Flaxseed supplementation (not dietary fat restriction) reduces prostate cancer proliferation rates in men presurgery. Cancer Epidemiol. Biomark. Prev. 2008, 17, 3577-3587. [CrossRef] [PubMed]

17. Dodin, S.; Cunnane, S.C.; Masse, B.; Lemay, A.; Jacques, H.; Asselin, G.; Tremblay-Mercier, J.; Marc, I.; Lamarche, B.; Legare, F.; et al. Flaxseed on cardiovascular disease markers in healthy menopausal women: A randomized, double-blind, placebo-controlled trial. Nutrition 2008, 24, 23-30. [CrossRef] [PubMed]

18. Faintuch, J.; Horie, L.M.; Barbeiro, H.V.; Barbeiro, D.F.; Soriano, F.G.; Ishida, R.K.; Cecconello, I. Systemic inflammation in morbidly obese subjects: Response to oral supplementation with alpha-linolenic acid. Obes. Surg. 2007, 17, 341-347. [CrossRef] [PubMed]

19. Faintuch, J.; Bortolotto, L.A.; Marques, P.C.; Faintuch, J.J.; Franca, J.I.; Cecconello, I. Systemic inflammation and carotid diameter in obese patients: Pilot comparative study with flaxseed powder and cassava powder. Nutr. Hosp. 2011, 26, 208-213. [PubMed]

20. Foster, M.; Petocz, P.; Samman, S. Inflammation markers predict zinc transporter gene expression in women with type 2 diabetes mellitus. J. Nutr. Biochem. 2013, 24, 1655-1661. [CrossRef] [PubMed]

21. Hallund, J.; Tetens, I.; Bugel, S.; Tholstrup, T.; Bruun, J.M. The effect of a lignan complex isolated from flaxseed on inflammation markers in healthy postmenopausal women. Nutr. Metab. Cardiovasc. Dis. 2008, 18, 497-502. [CrossRef] [PubMed]

22. Hutchins, A.M.; Brown, B.D.; Cunnane, S.C.; Domitrovich, S.G.; Adams, E.R.; Bobowiec, C.E. Daily flaxseed consumption improves glycemic control in obese men and women with pre-diabetes: A randomized study. Nutr. Res. 2013, 33, 367-375. [CrossRef] [PubMed]

23. Kaul, N.; Kreml, R.; Austria, J.A.; Richard, M.N.; Edel, A.L.; Dibrov, E.; Hirono, S.; Zettler, M.E.; Pierce, G.N. A comparison of fish oil, flaxseed oil and hempseed oil supplementation on selected parameters of cardiovascular health in healthy volunteers. J. Am. Coll. Nutr. 2008, 27, 51-58. [CrossRef] [PubMed]

24. Khalatbari, S.S.; Jamaluddin, R.; Tabibi, H.; Mohd Yusof, B.N.; Atabak, S.; Loh, S.P.; Rahmani, L. Effects of flaxseed consumption on systemic inflammation and serum lipid profile in hemodialysis patients with lipid abnormalities. Hemodial. Int. 2013, 17, 275-281. [CrossRef] [PubMed]

25. Kontogianni, M.D.; Vlassopoulos, A.; Gatzieva, A.; Farmaki, A.E.; Katsiougiannis, S.; Panagiotakos, D.B.; Kalogeropoulos, N.; Skopouli, F.N. Flaxseed oil does not affect inflammatory markers and lipid profile compared to olive oil, in young, healthy, normal weight adults. Metab. Clin. Exp. 2013, 62, 686-693. [CrossRef] [PubMed]

26. Lemos, J.R.; Alencastro, M.G.; Konrath, A.V.; Cargnin, M.; Manfro, R.C. Flaxseed oil supplementation decreases c-reactive protein levels in chronic hemodialysis patients. Nutr. Res. 2012, 32, 921-927. [CrossRef] [PubMed]

27. Nelson, T.L.; Stevens, J.R.; Hickey, M.S. Inflammatory markers are not altered by an eight week dietary alpha-linolenic acid intervention in healthy abdominally obese adult males and females. Cytokine 2007, 38, 101-106. [CrossRef] [PubMed]

28. Nordstrom, D.C.; Honkanen, V.E.; Nasu, Y.; Antila, E.; Friman, C.; Konttinen, Y.T. Alpha-linolenic acid in the treatment of rheumatoid arthritis. A double-blind, placebo-controlled and randomized study: Flaxseed vs. Safflower seed. Rheumatol. Int. 1995, 14, 231-234. [CrossRef] [PubMed]

29. Pan, A.; Demark-Wahnefried, W.; Ye, X.; Yu, Z.; Li, H.; Qi, Q.; Sun, J.; Chen, Y.; Chen, X.; Liu, Y.; et al. Effects of a flaxseed-derived lignan supplement on c-reactive protein, il-6 and retinol-binding protein 4 in type 2 diabetic patients. Br. J. Nutr. 2009, 101, 1145-1149. [CrossRef] [PubMed]

30. Rallidis, L.S.; Paschos, G.; Liakos, G.K.; Velissaridou, A.H.; Anastasiadis, G.; Zampelas, A. Dietary alpha-linolenic acid decreases c-reactive protein, serum amyloid a and interleukin-6 in dyslipidaemic patients. Atherosclerosis 2003, 167, 237-242. [CrossRef]

31. Rhee, Y.; Brunt, A. Flaxseed supplementation improved insulin resistance in obese glucose intolerant people: A randomized crossover design. Nutr. J. 2011, 10, 44. [CrossRef] [PubMed]

32. Vargas, M.L.; Almario, R.U.; Buchan, W.; Kim, K.; Karakas, S.E. Metabolic and endocrine effects of long-chain versus essential omega-3 polyunsaturated fatty acids in polycystic ovary syndrome. Metabolism 2011, 60, 1711-1718. [CrossRef] [PubMed]

33. Zong, G.; Demark-Wahnefried, W.; Wu, H.; Lin, X. Effects of flaxseed supplementation on erythrocyte fatty acids and multiple cardiometabolic biomarkers among chinese with risk factors of metabolic syndrome. Eur. J. Nutr. 2013, 52, 1547-1551. [CrossRef] [PubMed] 
34. International Prospective Register of Systemic Reviews. http://www.crd.york.ac.uk/prospero (accessed on 4 November 2015).

35. Adolphe, J.L.; Whiting, S.J.; Juurlink, B.H.; Thorpe, L.U.; Alcorn, J. Health effects with consumption of the flax lignan secoisolariciresinol diglucoside. Br. J. Nutr. 2010, 103, 929-938. [CrossRef] [PubMed]

36. Rodriguez-Leyva, D.; Dupasquier, C.M.; McCullough, R.; Pierce, G.N. The cardiovascular effects of flaxseed and its omega-3 fatty acid, alpha-linolenic acid. Can. J. Cardiol. 2010, 26, 489-496. [CrossRef]

37. Prasad, K. Flaxseed and cardiovascular health. J. Cardiovasc. Pharmacol. 2009, 54, 369-377. [CrossRef] [PubMed]

38. Peterson, J.; Dwyer, J.; Adlercreutz, H.; Scalbert, A.; Jacques, P.; McCullough, M.L. Dietary lignans: Physiology and potential for cardiovascular disease risk reduction. Nutr. Rev. 2010, 68, 571-603. [CrossRef] [PubMed]

39. Bloedon, L.T.; Szapary, P.O. Flaxseed and cardiovascular risk. Nutr. Rev. 2004, 62, 18-27. [CrossRef] [PubMed]

40. Jadad, A.R.; Moore, R.A.; Carroll, D.; Jenkinson, C.; Reynolds, D.J.; Gavaghan, D.J.; McQuay, H.J. Assessing the quality of reports of randomized clinical trials: Is blinding necessary? Control. Clin. Trials 1996, 17, 1-12. [CrossRef]

41. Follmann, D.; Elliott, P.; Suh, I.; Cutler, J. Variance imputation for overviews of clinical trials with continuous response. J. Clin. Epidemiol. 1992, 45, 769-773. [CrossRef]

42. Choi, J.; Joseph, L.; Pilote, L. Obesity and c-reactive protein in various populations: A systematic review and meta-analysis. Obes. Rev. 2013, 14, 232-244. [CrossRef] [PubMed]

43. Singh, T.; Newman, A.B. Inflammatory markers in population studies of aging. Ageing Res. Rev. 2011, 10, 319-329. [CrossRef] [PubMed]

44. Dewell, A.; Marvasti, F.F.; Harris, W.S.; Tsao, P.; Gardner, C.D. Low- and high-dose plant and marine (n-3) fatty acids do not affect plasma inflammatory markers in adults with metabolic syndrome. J. Nutr. 2011, 141, 2166-2171. [CrossRef] [PubMed]

45. Pearson, T.A.; Mensah, G.A.; Alexander, R.W.; Anderson, J.L.; Cannon, R.O., 3rd; Criqui, M.; Fadl, Y.Y.; Fortmann, S.P.; Hong, Y.; Myers, G.L.; et al. Markers of inflammation and cardiovascular disease: Application to clinical and public health practice: A statement for healthcare professionals from the centers for disease control and prevention and the american heart association. Circulation 2003, 107, 499-511. [PubMed]

46. Schwab, U.; Lauritzen, L.; Tholstrup, T.; Haldorssoni, T.; Riserus, U.; Uusitupa, M.; Becker, W. Effect of the amount and type of dietary fat on cardiometabolic risk factors and risk of developing type 2 diabetes, cardiovascular diseases, and cancer: A systematic review. Food Nutr. Res. 2014, 58. [CrossRef] [PubMed]

47. Li, K.; Huang, T.; Zheng, J.; Wu, K.; Li, D. Effect of marine-derived n-3 polyunsaturated fatty acids on c-reactive protein, interleukin 6 and tumor necrosis factor alpha: A meta-analysis. PLoS ONE 2014, 9, e88103.

48. Taylor, C.G.; Noto, A.D.; Stringer, D.M.; Froese, S.; Malcolmson, L. Dietary milled flaxseed and flaxseed oil improve n-3 fatty acid status and do not affect glycemic control in individuals with well-controlled type 2 diabetes. J. Am. Coll. Nutr. 2010, 29, 72-80. [CrossRef] [PubMed]

49. Plourde, M.; Cunnane, S.C. Extremely limited synthesis of long chain polyunsaturates in adults: Implications for their dietary essentiality and use as supplements. Appl. Physiol. Nutr. Metab. 2007, 32, 619-634. [CrossRef] [PubMed]

50. Haidari, F.; Mohammadshahi, M.; Borsi, S.H.; Haghighizadeh, M.H.; Malgard, S. Comparison of essential fatty acid intakes and serum levels of inflammatory factors between asthmatic and healthy adults: A case-control study. Iran. J. Allergy Asthma Immunol. 2014, 13, 335-342. [PubMed]

51. Bjermo, H.; Iggman, D.; Kullberg, J.; Dahlman, I.; Johansson, L.; Persson, L.; Berglund, J.; Pulkki, K.; Basu, S.; Uusitupa, M.; et al. Effects of $n-6$ pufas compared with sfas on liver fat, lipoproteins, and inflammation in abdominal obesity: A randomized controlled trial. Am. J. Clin. Nutr. 2012, 95, 1003-1012. [CrossRef] [PubMed]

52. Al-Lahham, S.H.; Peppelenbosch, M.P.; Roelofsen, H.; Vonk, R.J.; Venema, K. Biological effects of propionic acid in humans; metabolism, potential applications and underlying mechanisms. Biochim. Biophys. Acta 2010, 1801, 1175-1183. [CrossRef] [PubMed]

53. Jiao, J.; Xu, J.Y.; Zhang, W.; Han, S.; Qin, L.Q. Effect of dietary fiber on circulating c-reactive protein in overweight and obese adults: A meta-analysis of randomized controlled trials. Int. J. Food Sci. Nutr. 2015, 66, 114-119. [CrossRef] [PubMed]

54. Scott, K.P.; Antoine, J.M.; Midtvedt, T.; van Hemert, S. Manipulating the gut microbiota to maintain health and treat disease. Microb. Ecol. Health Dis. 2015, 26, 25877. [CrossRef] [PubMed]

55. Visser, M.; Bouter, L.M.; McQuillan, G.M.; Wener, M.H.; Harris, T.B. Elevated c-reactive protein levels in overweight and obese adults. JAMA 1999, 282, 2131-2135. [CrossRef] [PubMed] 
56. Ursoniu, S.; Sahebkar, A.; Andrica, F.; Serban, C.; Banach, M. Effects of flaxseed supplements on blood pressure: A systematic review and meta-analysis of controlled clinical trial. Clin. Nutr. 2015. [CrossRef] [PubMed]

57. Gould, A.L.; Davies, G.M.; Alemao, E.; Yin, D.D.; Cook, J.R. Cholesterol reduction yields clinical benefits: Meta-analysis including recent trials. Clin. Ther. 2007, 29, 778-794. [CrossRef] [PubMed]

58. Sahebkar, A.; Serban, C.; Ursoniu, S.; Banach, M. Effect of garlic on plasma lipoprotein(a) concentrations: A systematic review and meta-analysis of randomized controlled clinical trials. Nutrition 2016, 32, $33-40$. [CrossRef] [PubMed]

59. Serban, C.; Sahebkar, A.; Antal, D.; Ursoniu, S.; Banach, M. Effects of supplementation with green tea catechins on plasma C-reactive protein concentrations: A systematic review and meta-analysis of randomized controlled trials. Nutrition 2015, 31, 1061-1071. [CrossRef] [PubMed]

60. Ursoniu, S.; Sahebkar, A.; Serban, M.C.; Banach, M. Lipid profile and glucose changes after supplementation with astaxanthin: A systematic review and meta-analysis of randomized controlled trials. Arch. Med. Sci. 2015, 11, 253-266. [CrossRef] [PubMed]

61. Banach, M.; Rizzo, M.; Toth, P.P.; Farnier, M.; Davidson, M.H.; Al-Rasadi, K.; Aronow, W.S.; Athyros, V.; Djuric, D.M.; Ezhov, M.V.; et al. Statin intolerance-An attempt at a unified definition. Position paper from an International Lipid Expert Panel. Arch. Med. Sci. 2015, 11, 1-23. [CrossRef] [PubMed]

(C) 2016 by the authors; licensee MDPI, Basel, Switzerland. This article is an open access article distributed under the terms and conditions of the Creative Commons by Attribution (CC-BY) license (http://creativecommons.org/licenses/by/4.0/). 